\title{
CORRECTION
}

View Article Online

View Journal I View Issue

\section{Correction: Investigation of plasmonic signal enhancement based on long range surface plasmon resonance with gold nanoparticle tags}

Cite this: J. Mater. Chem. C, 2016,

4, 10562

Chih-Tsung Yang, ${ }^{a}$ Lin $\mathrm{Wu}^{{ }^{*} \mathrm{~b}}$ Ping $\mathrm{Bai}^{\mathrm{b}}$ and Benjamin Thierry ${ }^{\mathrm{a}}$

DOI: 10.1039/c6tc90191c

Correction for 'Investigation of plasmonic signal enhancement based on long range surface plasmon resonance with gold nanoparticle tags' by Chih-Tsung Yang et al., J. Mater. Chem. C, 2016, 4, 9897-9904.

www.rsc.org/MaterialsC

The affiliation details of the corresponding author, Benjamin Thierry, are incorrect in the published version of this article. Benjamin Thierry is affiliated to address ${ }^{a}$, the Future Industries Institute at the University of South Australia, as indicated in this correction article.

The Royal Society of Chemistry apologises for these errors and any consequent inconvenience to authors and readers.

\footnotetext{
${ }^{a}$ Future Industries Institute, University of South Australia, Mawson Lakes Campus, Mawson Lakes, South Australia, Australia. E-mail: Benjamin.thierry@unisa.edu.au; Fax: +6188302 3683; Tel: +61883023689

${ }^{b}$ Electronics and Photonics Department, Institute of High Performance Computing, Agency for Science, Technology, and Research (A*STAR), 138632, Singapore
} 